\title{
A Study of Laser Effectiveness in Injured Tissues Regeneration
}

\author{
Marcus Vinicius de Mello Pinto ${ }^{*}$, Aline Ronis Sampaio', Miriam Viviane Baron², \\ Carolina Macedo Alves Moreira ${ }^{3}$, Carolina Gonçalves Pinheiro4,5, Michele Paula dos Santos ${ }^{2,6}$, \\ Andres Felipe Mantilla Santamaria ${ }^{2}$, Cristine Brandenburg7 ${ }^{7}$, Nathália Ken Pereira Iketani ${ }^{8}$, \\ Mara Alessandra Porto dos Reis Oliveira9 , Alexandre Sancho' ${ }^{10}$, Felice Picariello" ${ }^{11}$, \\ Esteban Fortuny'2, Juliano Tibola ${ }^{13}$, Nilton Petrone Vilardi Jr. ${ }^{14}$ \\ ${ }^{1}$ Celulare Institute, Petrópolis, Rio de Janeiro, Brazil \\ ${ }^{2}$ School of Medicine, Pontifical Catholic University of Rio Grande do Sul (PUC/RS), Porto Alegre, Brazil \\ ${ }^{3}$ Dr. Daniel Thomaz Clinic, Uberlandia, Minas Gerais, Brazil \\ ${ }^{4}$ Faculty of Medicine of ABC (FMABC), Santo André, Brazil \\ ${ }^{5}$ Vale do Salgado Faculty (FVS), Ceará, Brazil \\ ${ }^{6}$ School of Medicine, Industrial University of Santander (UIS), Bucaramanga, Colombia \\ ${ }^{7}$ Federal University of Ceará (UFC), Fortaleza, Brazil \\ ${ }^{8}$ Hospital Beneficiente Portuguesa of Belém, Pará, Brazil \\ ${ }^{9}$ Clínica Instituto de Cirurgia Plástica Vênus, Barreiras, Bahia, Brazil \\ ${ }^{10}$ Unigranrio, Rio de Janeiro, Brazil \\ ${ }^{11}$ da Universita Federico II di Napoli, Italia e Pesquisador do Internacional Research Group, Rio Grande do Norte, Brazil \\ ${ }^{12}$ Universidad Finis Terrae, Santiago Chile \\ ${ }^{13}$ UDESC, Florianopolis, SC, Brazil \\ ${ }^{14}$ Fluminense Football Club, Rio de Janeiro, RJ, Brazil \\ Email: ^marcuspinto1966@gmail.com
}

How to cite this paper: de Mello Pinto, M.V., Sampaio, A.R., Baron, M.V., Moreira, C.M.A., Pinheiro, C.G., dos Santos, M.P., Santamaria, A.M.F., Brandenburg, C., Iketani, N.K.P., dos Reis Oliveira, M.A.P., Sancho, A., Picariello, F., Fortuny, E., Tibola, J. and Vilardi Jr., N.P. (2021) A Study of Laser Effectiveness in Injured Tissues Regeneration. Journal of Biosciences and Medicines, 9, 55-63.

https://doi.org/10.4236/jbm.2021.93007

Received: September 20, 2020

Accepted: March 21, 2021

Published: March 24, 2021

\begin{abstract}
This study aimed to understand the use of low level laser in the regeneration of injured tissues. Also to design our own opinion on the subject, as chemists. Laser is nothing more than a light with very special characteristics that grant it therapeutic properties. We can observe the existence of three different types of laser, being one of them the therapeutic laser, which is used in substitution for medications or along with them. Another type of laser is the surgical one and, in addition to these, there is a diagnostic type. A great advantage is that, instead of taking the medicine, the patient's own body can be activated by the laser to produce certain substances that can often replace the drugs. This is a literature review emphasizing the use of low level laser. Thus, the reflections from this study can contribute to the amplification of the production of knowledge that aims at the resignification of the use of laser in therapy. Greater attention was given to two types of laser radiation: $\mathrm{He}-\mathrm{Ne}$ and $\mathrm{As}-\mathrm{Ga}$,
\end{abstract}


Copyright (c) 2021 by author(s) and Scientific Research Publishing Inc. This work is licensed under the Creative Commons Attribution International License (CC BY 4.0).

http://creativecommons.org/licenses/by/4.0/ both presenting a high therapeutic potential in superficial and deep injures. However, the He-Ne laser excels in superficial lesions, whereas the As-Ga laser does so in deep injures, such as articular, muscular, etc.

\section{Keywords}

Laser, Injury, Regeneration

\section{Introduction}

As science has advanced over the last decades, laser has become a great pioneer and ally of medicine, since it has a great effectiveness in most treatments it is used, with an emphasis on regeneration of injured tissues [1] [2].

One of its major advantages is that, instead of taking the medicine, the patient's own body can be activated by the laser to produce certain substances that can often replace the drugs [3] [4] [5]. The main objective of this paper is to demonstrate the low level laser performance in injured tissue regeneration emphasizing the chemical properties and the differences between the different types of laser. We'll present the device properties, the kinds of radiation, the interaction between this radiation and molecular and cell structures and of the human body and the physiological effects that occur in these tissues, so that the reader can understand how laser operates in injured tissues [4] [6].

This paper is the result of a literature research that indicates to the reader the scientific treatment for the investigated phenomenon, according to the various theoretical frameworks [5]. It includes the definition and contrast of concepts, the mention of other papers already done on the subject and the theory that supports it. We point, throughout the text, the theoretical limitations of scientific knowledge developed so far on the phenomenon investigated. We hope this study contributes beyond the reflection on concepts and theories on laser [4] [7]. It is extremely important to stir in future researchers the interest in a topic as complex and important for humanity [8].

\section{A Little Bit of History}

Back in 1900, Planck found that light, or any radiation, could only be beamed in "packages" or "quanta"-hence the name Quantum Mechanics-that is, light is a "particle (or photon) stream". This fact was proven by Einstein through the theory of the photoelectric effect, in which, in 1917, he presented the physical principles of Stimulated Emission, upon which the laser phenomenon is supported [5] [6].

In 1960, a new word, laser, an acronym for Light Amplification by Stimulated Emission of Radiation, was added to the vocabulary. This invention was based on a variety of ideas and facts that originated in different branches of Physics and Engineering, but mainly in phenomena of Atomic and Molecular Physics 
that can not be explained by Classical Physics. It was the application of Einstein's Quantum Mechanics to Electronics which allowed the blossoming of what we call Quantum Electronics, a field that has developed after World War II and which led to the discovery of many devices, starting with the transistor in the '40s, culminating in the discovery of the laser in the '60s [8].

In the late '40s, early '50s, Charles Townes, a professor at Columbia University in New York at the time, was running spectroscopic studies of molecules using microwave radiation. He intended to produce microwaves shorter than those used in radars of World War II, and had the idea of using molecules and their stimulated radiation (concept introduced by Einstein in 1917). He and his colleagues were successful, producing stimulated radiation of $1 \mathrm{~cm}$ wavelength, which was named maser, referring to stimulated radiation in the microwave region. The maser was, therefore, the precursor of laser. At the end of the '50s, it was realized that these studies could be extended to the spectral range that goes from the microwave to the visible light. Again, Townes and his colleague Arthur Schawlow were able to prove theoretically that it was possible to use atoms to generate an optical maser, which was called Laser, that is, a maser that produces radiation in the visible region of the electromagnetic spectrum, which we know by light. Then, only in 1950, Townes et al. managed to build an oscillator operating in the millimeter wave band; it was the first master [9].

In 1958, Townes et al. demonstrated the possibility to build a laser. This theoretical proof was ensured in practice in 1960 by Maiman, who was the first to compound a ruby laser emitter (first solid laser). And Javan was the first to produce the laser gas, from a mixture of Helium and Neon. According to a data collection made by Rodrigues et al., (1998), in 1961 at the Presbyterian Hospital in New York, the first laser surgery was held successfully: the removal of a small retinal tumor. Since this and other surgical experiments, it was evident that laser stimulates accelerated healing [9] [10].

In 1962, the first semiconductor laser was developed. Two years later, it was the time for gas laser and the first molecular carbon dioxide laser. In 1965, Sinclair et al. adapted laser radiation to therapeutic practice [2] [11] [12]. During their research noted that the treatment of various types of chronic ulcer was the first application of low intensity laser tested in humans during the late ' $60 \mathrm{~s}$ and early '70s, when sources of He-Ne and doses up to $4 \mathrm{j} / \mathrm{cm}^{2}$ were used. Based on the success achieved in these first studies, in terms of faster healing and pain reduction, the modality grew popular in this application. Founded on the work of Mester in animals and patients, the subsequent decade witnessed the promotion of irradiation by He-Ne laser as the treatment of choice for a number of disorders. The diffusion of small and compact laser emitting photodiodes promoted an upsurge in the use of this therapy which is known in the Western world as low level or low intensity laser therapy [13] [14].

Second, Rodrigues et al., 1998, Strictly with the so-called scientific-technological revolution, it was shown that this therapeutic approach should not be applied 
without deep understanding of biophysical phenomena that enable and trigger the effects of therapy [15].

\section{What Laser Is}

Laser is an acronym for Light Amplification by Stimulated Emission of Radiaton.

Laser consists of a coherent beam of light that focuses on a small well-defined area. There is virtually no dispersion-scattering-in this beam, unlike a lamp, whose light rays are spread covering a comprehensive area. Any substance within that ray evaporates instantly. Briefly, laser works as follows (Figure 1): When an atom is excited enough to reach its last valence shell (its excited state or metastable level) it leaves its gap-its place of origin-empty, and in returning to this gap (not necessarily the same electron) emits electromagnetic radiation [15].

The time frame in which the electron remains out of its gap may vary and this is the time that determines the energy dispersion, that is, the longer the electron is out, the lesser its dispersion will be [1].

\section{Characteristics of Laser Radiation}

Laser means Light Amplification by Stimulated Emission of Radiation. The laser beams are produced by a mixture of helium/neon $(6328 \mathrm{~nm})$. The mixture helium/neon produces a red light and the infrared mixture does not produce light. In order to describe a laser light, we must measure the wavelength in nanometers, the total pulse duration, the repetition rate and total exposure time, the intensity of energy and power in joules per square centimeter and irradiation in watts per square centimeter.

The monochromaticity causes the laser beam to be absorbed by a single color; for instance: a red beam $(\mathrm{He} / \mathrm{Ne})$ is absorbed by red areas of the body such as the capillaries [9]. It permeates the cutaneous and subcutaneous structure without being absorbed by it and without communicating its energy, which will be communicated only in the capillaries. In turn, the intensity of the biological reaction depends on the wavelength reabsorption, reflection and transmission; also on energy density, exposure time and blood flow [16].

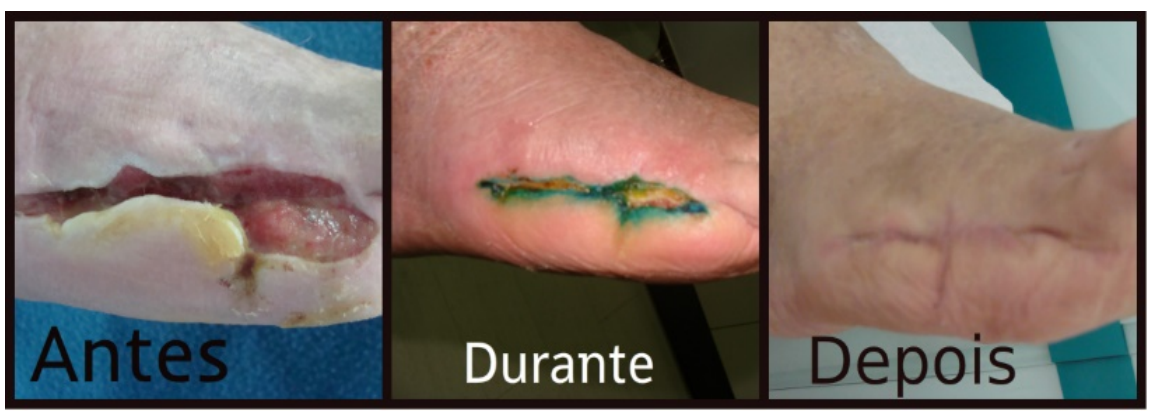

Figure 1. Region of amputation of metatarsus in left lower limb, a result of using this patient was treated with the scar acceleration methodology, M.A.C, using monodoses of lasers, photo provided by the Celulare Institute, Itaipava, Petropolis, RJ Brazil. 
The radiation generated by the laser devices for therapeutic use differs from the radiation generated by other sources (e.g., infrared lamps) in three aspects:

\subsection{Monochromaticity}

The light produced by a laser is monochromatic, that is, it has a single color. Most of the radiation emitted by the therapeutic device is grouped around a single wavelength, with a very limited range of waveband. In contrast, the light generated by other sources is formed by a wide range of wavelengths, sometimes ranging from the ultraviolet to the infrared, resulting in the sensation of white light, when the light collides with the retina of a human observer. The wavelength is a critical factor in determining the therapeutic effects produced by laser treatments, since this parameter determines which specific biomolecules absorb the incident radiation and, therefore, the photobiological interaction underlying any particular therapeutic effect [16].

\subsection{Collimation}

In laser light, the beams or photons produced by the laser device are, for all practical purposes, parallel; any divergence in the emitted radiation along the distance covered is practically nonexistent. This property holds the optical power of the device bundled in a relatively small area over considerable distances and, to some extent, even during the path through the tissue [2].

\subsection{Spatial Coherence}

Laser obeys the laws of Physics. Specific substances are electrically stimulated to emit radiations that produce higher levels of energy [2].

\subsection{Coherence}

The light emitted by laser devices is also in phase and thus, along with the two unique properties outlined above, the troughs and peaks of the emitted light waves fit perfectly in time (temporal coherence) and space (spatial coherence) $[6]$.

\section{Mechanism of Action and Effects of Laser Radiation}

\subsection{Studies on the Action of Laser Radiation}

For laser radiation to have any effect on the human body, it has to be absorbed; that is, an interaction between this radiation and the molecular and cellular structures of the human body has to occur [2]. This point seems extremely obvious, but there lie some complex issues:

- People are very different from each other. They have different quantities of absorbing molecules and, moreover, the spatial arrangement of these absorption elements, which is as important as their amounts, also varies greatly from person to person.

- Even if we consider a single person we will observe that different regions of 
the body have different quantities of absorbing molecules and the spatial arrangement thereof also varies.

Considering the above, we can easily establish a pattern of electromagnetic waves behavior striking the human body. Each subject has a specific way to react to these stimuli. Such responses vary to the extent to which personal differences and the different regions of the body of an individual are considered.

Mester, a pioneer in the use of low level laser, evidenced numerous theoretical aspects in his studies, including:

- By observing the results of laser applications in electron microscopy healing process, he pointed that there was an increase in fibroblasts, collagen fibers, corpúsculos intracelulares do tipo lisossoma and intracellular vesicles.

- Verified, via histochemical means, the following reactions in the wound healing processes in female rats in which there were ratas.

\subsection{Laser Penetration and Absorption}

Factors such individual differences, part of the body treated or even details on the laser application form may interfere significantly in the penetration and absorption of laser, causing variations from person to person. Even in a single individual, different body areas contain a greater or lesser amount of absorbent structures (Pinto et al., 2011). Within the same individual, the amount of absorbed radiation may vary according to the irradiated body region. Also, a black patient would absorb more radiation than a white one, for instance, due to the greater amount of pigments. It also seems that the nutritional state of the individual has the ability to interfere in the quantity of absorbed radiation [2] [6] [7] [11].

\subsection{Laser Radiation Action and Effects}

Firstly, the differences between action and effects, concepts often confused and taken as one, must be pointed out [2].

- Action: Form of interaction with the body.

- Effects: Consequences of this interaction.

In the case of laser radiation, the form of interaction with the body (action) is basically the incorporation of the energy input contained in the beam.

As a result of this interaction, we can list:

\section{Primary effects of laser radiation:}

The primary effects of level laser radiation are divided into biochemical, bioelectric and bioenergetic.

\section{- Biochemical effect:}

Essentially, the biochemical effects of laser radiation include:

Release of preformed substances:

As a result of the incorporation of laser radiation, the release of preformed substances such as histamine, serotonin and bradykinin takes place.

We outline no references to the production of these substances, only to the release of part of the contingent already produced. 
Change in enzymatic relations. The incorporation of laser radiation energy input provides stimulatory or inhibitory changes in normal enzymatic reactions, such as the production of ATP (adenosine triphosphate) and prostaglandins synthesis.

Another important biochemical effect of laser radiation is the increased, a fact which determines important advantages in therapeutic effects [2] [6] [7] [16].

\section{- Bioelectric effect}

The interior of cells is electrically negative as compared to the cell exterior. This difference in potential is due to the presence of different concentrations of positive or negative ions inside or outside the cell [2] [6]. The biochemical effect occurs through a cascade of photobiological events that directly modify the cellular pathological state.

Considering this electrical and concentration gradient, there is a natural tendency to neutralization by diffusion, which is not complete only because of a mechanism called sodium-potassium pump [14].

The sodium-potassium pump constantly works against the existing electrical and concentration gradients, consuming, for this energy from ATP. Thus, the difference in electrical potential between the cell interior and exterior is maintained more efficiently.

Therefore, the bioelectric effect of laser radiation comes down to the maintenance of membrane potential [6].

It is also possible to conclude that the maintenance of membrane potential is favored by laser radiation from the direct interference on ion mobility [1] [2].

\section{Conclusion}

This study aimed to demonstrate the low level laser performance in the regeneration of damaged tissues. At first, there was a need to outline device properties, kinds of radiation, the interaction of this radiation with molecular and cellular structures of the human body and the physiological effects in such tissues, so that the reader can understand how laser works and performs in injured tissues. Secondly, many papers have provided very important information regarding the proposed theme, in which results of experimental studies have demonstrated numerous benefits in using low level laser in injured tissues, favoring a major breakthrough in clinical practice in several areas, such as: traumatic orthopedic (post-traumatic processes), dermatologic (decubitus ulcers, burns and wounds), rheumatologic (rheumatoid arthritis), neurological (postherpetic neuralgia, sciatic neuralgia, clonus and activity in the sympathetic nervous system) and others, not being unanimous as there were results (though outnumbered) showing that these beneficial effects did not occur. This fact can be explained by the great limitation of regeneration of biological tissues injured in humans compared to the experimental animals. If we bear in mind the ideal means to use laser (as wavelength, waveform, intensity, polarity, coherence and dosage) and the choice of the program regarding: correct laser type, duration and number of sessions, fea- 
tures of the tissue to be irradiated and respect the organic state of each individual, a faster tissue regeneration can be obtained by accelerating the collagen synthesis and cellular metabolism, facilitating the clinical process, given the fact that when laser is introduced in a therapeutic conduct, the results achieved are generally favorable.

\section{Acknowledgements}

This study was funded in part by the Coordination of Improvement of Higher Level Personnel, Brazil (CAPES), Finance Code 001. Thanks to the Brazilian company Ecco Fibras in the person of Mr. Henrique Trajano for the scientific support of this article.

\section{Conflicts of Interest}

The authors declare having no conflict of interest regarding this article.

\section{References}

[1] Calzavara-Pinton, P.G., Venturini, M. and Sala, R. (2007) Photodynamic Therapy: Update 2006. Part 1: Photochemistry and Photobiology. The Journal of the European Academy of Dermatology and Venereology, 21, 293-302. https://doi.org/10.1111/j.1468-3083.2006.01902.x

[2] Pinto, M.V.M. (2011) Fototerapia-Aspectos Clinicos Da Reabilitacao. Ed. Andreoli.

[3] Sperandio, F.F., Huang, Y.-Y. and Hamblin, M.R. (2013) Antimicrobial Photodynamic Therapy to Kill Gram-Negative Bacteria. Recent Patents on Anti-Infective Drug Discovery, 8, 108-120. https://doi.org/10.2174/1574891X113089990012

[4] Gonçalves, R.V., Sarandy, M.M., da Matta, S.L.P., Novaes, R.D. and Pinto, M.V.M. (2013) Comparative Study of the Effects of Laser Photobiomodulation and Extract of Brassica oleracea on Skin Wounds in Wistar Rats: A Histomorphometric Study. Pathology_Research and Practice, 209, 648-653. https://doi.org/10.1016/j.prp.2013.07.006

[5] Firczuk, M., Nowis, D. and Golab, J. (2011) PDT-Induced Inflammatory and Host Responses. Photochemical \& Photobiological Sciences, 10, 653-663. https://doi.org/10.1039/c0pp00308e

[6] Zhu, T.C. and Finlay, J.C. (2008) The Role of Photodynamic Therapy (PDT) Physics. Medical Physics, 35, 3127-3136. https://doi.org/10.1118/1.2937440

[7] Farouk, A.H. and Al-Watban, B.L. (2003) Polychromatic LED Therapy in Burn Healing of Non-Diabetic and Diabetic Rats. Journal of Clinical Laser Medicine \& Surgery, 5, 249-258. https://doi.org/10.1089/104454703322564451

[8] Pinto, M., Sampaio, A., Gonçalves, R., Veiga, C., Rocha, L., Costa, D., Lopes, L., Ferreira, R., Valim, P., Chaveiro, K., Sathler, E., Vieira, R. and Bernardes, I. (2017) Estudo dos efeitos da terapia fotodinâmica (TFD), em feridas cutâneas induzidas por cicatrizes em ratos Wistar: The New Clinical Perspective for Ulcers. Modern Research in Inflammation, 6, 1-8. https://doi.org/10.4236/mri.2017.61001

[9] Vladimirov, Y.A., Osipov, A.N. and Klebanov, G.I. (2004) Photobiological Principles of Therapeutic Applications of Laser Radiation. Biochemistry, 69, 81-89. https://doi.org/10.1023/B:BIRY.0000016356.93968.7e

[10] Seung, A., Park, K.H., Choi, J.W., Kwon, J.K., Doo, K.L., Mi, S.S., et al. (2007) A 
Prospective, Randomized, Placebo-Controlled, Double-Blinded, and Split-Face Clinical Study on LED Phototherapy for Skin Rejuvenation: Clinical, Profilometric, Histologic, Ultrastructural, and Biochemical Evaluations and Comparison of Three Different Treatment Settings. Journal of Photochemistry and Photobiology, 88, 51-67. https://doi.org/10.1016/j.jphotobiol.2007.04.008

[11] Gonçalves, R.V., Novaes, R.D., Matta, S.L., Benevides, G.P., Faria, F.R. and Pinto, M.V.M. (2010) Estudo comparativo dos efeitos da fotobiomodulação a laser de arseneto de gálio-alumínio e óleo cicatrizante em feridas cutâneas em ratos wistar: Estudo histomorfométrico. Photomedicine and Laser Surgery, 28, 597-602.

https://doi.org/10.1089/pho.2009.2669

[12] Rocha, L.L.V., Pinto, M.V.M., Maria, J., Vieira, A.J.D., Martins, P.R., Costa, K.F.F.V. and Valerio, L.R.S. (2007) Efeito da Terapia laser sobre o modelo experimental de Inflamação Granulomatosa. Fisioterapia Brasil, 8, 335-341.

https://doi.org/10.33233/fb.v8i5.1801

[13] Klebanov, G.I., Klebanov, G.I., Shuraeva, N., Chichuk, T.V., Osipov, N.A., Rudenko, T.G., Shekhter, A.B., et al. (2005) A Comparative Study of the Effects of Laser and Light-Emitting Diode Irradiation on the Wound Healing and Functional Activity of Wound Exudate Leukocytes. Biofizika, 34, 129-132.

[14] Vinck, E.M., Cagnie, B.J., Cornelissen, M.J., Declercg, H.A. and Cambier, D.C. (2005) Green Light Emitting Diode Irradiation Enhances Fibroblast Growth Impaired by High Glucose Level. Photomedicine and Laser Surgery, 2, 167-171. https://doi.org/10.1089/pho.2005.23.167

[15] Chung, T.Y., Peplow, P.V. and Baxter, G.D. (2010) Fotobioestimulação a laser na cicatrização de feridas: Definindo uma resposta à dose para feridas imobilizadas em camundongos diabéticos. Lasers in Surgery and Medicine, 42, 656-664.

[16] Russell, B.A., Kellett, N. and Reilly, L.R. (2005) A Study to Determine the Efficacy of Combination LED Light Therapy (633 nm and $830 \mathrm{~nm}$ ) in Facial Skin Rejuvenation. Journal of Cosmetic and Laser Therapy, 7, 196-200.

https://doi.org/10.1080/14764170500370059 